Marquette University

e-Publications@Marquette

Biomedical Engineering Faculty Research and

Publications

Biomedical Engineering, Department of

$3-1-2003$

Nonlinear Elastic Material Property Estimation of Lower Extremity Residual Limb Tissues

Ergin Tönük

Middle East Technical University

M. Barbara Silver-Thorn

Marquette University, barbara.silver-thorn@marquette.edu

Accepted version. IEEE Transactions on Neural Systems and Rehabilitation Engineering, Vol. 11, No. 1 (March 2003): 43-53. DOI. (C) 2003 Institute of Electrical and Electronics Engineers (IEEE). Used with permission. 


\title{
Nonlinear Elastic Material Property Estimation Of Lower Extremity Residual Limb Tissues
}

\author{
Ergin Tönük \\ Department of Mechanical Engineering, Middle East Tech. University, Ankara, Turkey \\ M. Barbara Silver-Thorn \\ Department of Biomedical Engineering, Marquette University, Milwaukee, WI
}

\begin{abstract}
The interface stresses between the residual limb and prosthetic socket have been studied to investigate prosthetic fit. Finite-element models of the residual limb-prosthetic socket interface facilitate investigation of the mechanical interface and may serve as a potential tool for future prosthetic socket design. However, the success of such residual limb models to date has been limited, in large part due to inadequate material formulations used to approximate the mechanical behavior of residual limb soft tissues. Nonlinear finite-element analysis was used to simulate force-displacement data obtained during in vivo rate-controlled $(1,5$, and $10 \mathrm{~mm} / \mathrm{s})$ cyclic indentation of the residual limb soft tissues of seven individuals with transtibial amputation. The finite-element models facilitated determination of an appropriate set of nonlinear elastic material coefficients for bulk soft tissue at discrete clinically relevant test locations. Axisymmetric finite-element models of the residual limb bulk soft tissue in the vicinity of the test location, the socket wall and the indentor tip were developed incorporating contact analysis, large displacement, and large strain, and the James-Green-Simpson nonlinear elastic material formulation. Model dimensions were based on medical imaging studies of the residual limbs. The material coefficients were selected such that the normalized sum of square error (NSSE) between the experimental and finite-element model indentor tip reaction force was minimized. A total of $95 \%$ of the experimental data were simulated using the James-Green-Simpson material formulation with an NSSE
\end{abstract}

IEEE Transactions on Neural Systems and Rehabilitation Engineering, Vol 11, No. 1 (March 2003): 43-53. DOI. This article is @ Institute of Electrical and Electronics Engineers (IEEE) and permission has been granted for this version to appear in e-Publications@Marquette. Institute of Electrical and Electronics Engineers (IEEE) does not grant permission for this article to be further copied/distributed or hosted elsewhere without the express permission from Institute of Electrical and Electronics Engineers (IEEE). 
NOT THE PUBLISHED VERSION; this is the author's final, peer-reviewed manuscript. The published version may be accessed by following the link in the citation at the bottom of the page.

less than 5\%. The respective James-Green-Simpson material coefficients varied with subject, test location, and indentation rate. Therefore, these coefficients cannot be readily extrapolated to other sites or individuals, or to the same site and individual some time after testing.

\section{Nomenclature}

\begin{tabular}{|c|l||}
\hline \hline$C_{i}$ & Nonlinear elastic material coefficients; subscript indicates the order in strain invariant. \\
\hline \hline$C_{i j}$ & $\begin{array}{l}\text { Nonlinear elastic material coefficients in James-Green-Simpson material model; } i=\text { order in } \\
\text { first strain invariant } I_{1} ; j=\text { order in second strain invariant } I_{2} .\end{array}$ \\
\hline \hline$E_{i j}$ & Components of Green-Lagrange finite strain tensor. \\
\hline \hline$F$ & Force. \\
\hline \hline$F_{\exp }$ & Experimentally measured indentor reaction force. \\
\hline \hline$F_{f e}$ & Finite-element indentor reaction force. \\
\hline \hline$F_{\text {exp }}$ & Maximum experimental indentor reaction force. \\
\hline \hline$I_{1}, I_{2}$ & First and second invariants of Green-Lagrange finite strain tensor. \\
\hline \hline & Normalized sum of square error. \\
\hline \hline$r$ & Radial coordinate in cylindrical coordinate system. \\
\hline \hline$u_{i}$ & Components of material displacement vector. \\
\hline \hline$W$ & Strain energy density (energy per undeformed volume). \\
\hline \hline$X_{i}$ & Components of position vector of a material particle at initial (undeformed) configuration. \\
\hline \hline$x_{i}$ & Components of position vector of a material particle at current (deformed) configuration. \\
\hline \hline$Z$ & Axial coordinate of cylindrical coordinate system. \\
\hline \hline$\Lambda_{i} \lambda_{i}$ & Stretch (former is Malvern's [60] notation in Lagrangian sense). \\
\hline \hline$\theta$ & Angular coordinate of the cylindrical coordinate system. \\
\hline \hline & \\
\hline
\end{tabular}

\section{SECTION I.}

\section{Introduction}

To ambulate effectively, lower limb amputees require a prosthesis. Many amputees, however, are not satisfied with the fit of their prosthesis. ${ }^{1}$ The poor fit may cause discomfort and pain for the amputee, as well as potential tissue degradation and/or impaired mobility.

Several researchers have looked at the interface stress distribution between the residual limb and prosthetic socket as a means of objectively describing prosthetic fit. Potential problems in prosthetic fit might thereby be identified and corrected before

IEEE Transactions on Neural Systems and Rehabilitation Engineering, Vol 11, No. 1 (March 2003): 43-53. DOI. This article is (C) Institute of Electrical and Electronics Engineers (IEEE) and permission has been granted for this version to appear in e-Publications@Marquette. Institute of Electrical and Electronics Engineers (IEEE) does not grant permission for this article to be further copied/distributed or hosted elsewhere without the express permission from Institute of Electrical and Electronics Engineers (IEEE). 
significant tissue damage ensues. Both Sanders ${ }^{2}$ and Silver-Thorn et al. ${ }^{3}$ present extensive reviews of prosthetic interface stress investigations. Many investigators measured prosthetic interface stresses using a variety of "pressure" transducers. In general, these measurements were limited to relatively small areas of the residual limb and, with the exception of Sanders and Daly,, ${ }^{4,5}$ Sanders et al., ${ }^{6,7}$ and Zhang et al., ${ }^{8}$ who measured both normal and shear stress, these measurements were of the normal stress (pressure) distribution. These interface stress-measuring techniques required fabrication of special sockets that were appropriate for scientific investigation only and were not for routine clinical use.

Two commercially available devices for measurement of prosthetic interface pressures in a clinical environment are the Rincoe Socket Fitting System (R. G. Rincoe \& Associates, Golden, CO) and the Pliance High Resolution Pad (Novel Electronics, Inc., St. Paul, MN). These systems do not require fabrication of special test sockets or modification of the current prosthesis. However, these devices provide interface pressure measures at a limited number of sites and yield no information regarding the shear stress.

Due to these technological limitations, researchers have used computer models to estimate the prosthetic interface stresses (review articles ${ }^{3,9}$ and ${ }^{10}$ ). Computer models, typically finite-element analyses, allow investigation of both the normal and shear stress distributions for the entire residual limb-prosthetic socket interface.

Finite-element models of the residual limb and the prosthetic socket of individuals with transtibial $3,9-10,11,12,13,14,15,16,17,18$ and transfemoral $19-20,21,22,23,24,25,26$ amputation have been used to investigate residual limb-prosthetic socket biomechanics and to estimate the interface stress distribution. These models have the potential to provide insight into prosthetic socket design principles and alternative design protocols.

Although these investigations provided some insight regarding residual limbprosthetic socket interaction, none were successful in accurately estimating the interface stresses. The in vivo soft tissue indentation studies performed by Houston et al.,16 Vannah and Childress, ${ }^{27}$ Silver-Thorn, ${ }^{28}$ and Zheng and Mak $^{29}$ reveal that the compressive behavior of lower extremity soft tissues is nonlinear and viscoelastic, as opposed to the linear elastic material approximation used in the majority of the aforementioned finite-element analyses. Furthermore, the compressive soft tissue behavior varies among subjects and between test locations for the same subject. Therefore, it is necessary to determine the nonlinear material behavior of the soft tissue in compression for each individual at various locations 
on the residual limb for accurate computer simulation. These nonlinear elastic material formulations can then be extended to simulate the viscoelastic response.

Finite-element-based material identification techniques have been used by many investigators to determine the material properties of various structures, including biological tissues. ${ }^{30,31-32,33,34,35,36,37,38,39,40,41}$ In general, these "inverse methods" assume a constitutive equation for the material, and estimate the material coefficients by simulating experimental force-deformation data with a computer model (review $\left.{ }^{41}\right)$.

The purpose of this research is to estimate the nonlinear elastic material properties of the residual limb soft tissues during the loading portion of in vivo indentation using inverse methods. Various Mooney-type material formulations have been used for modeling the nonlinear elastic response of bulk muscular soft tissue to in vivo indentation. ${ }^{27,42-43,44,45}$ It is hypothesized that the James-Green-Simpson (or third-order deformation Mooney) ${ }^{46-}$ $47,48,49,50$ nonlinear elastic material model can approximate the observed nonlinear elastic behavior of the bulk soft tissue of the residual limbs of individuals with trans-tibial amputation.

\section{SECTION II.}

\section{Methods}

Force-displacement loading data obtained during cyclic indentation of the residual limbs of seven individuals ${ }^{1}$. with transtibial amputation were simulated using finiteelement analysis. For each subject, the residual limb soft tissues at 9 to 11 test locations relevant to prosthetic socket rectification were tested at rates 1,5 , and $10 \mathrm{~mm} / \mathrm{s}$ on separate occasions. The force-displacement data (cycles 6-10; cycles 1-5 served to precondition the tissues) during loading were regressed to a third-order polynomial. ${ }^{28,51}$

These loading data were simulated using axisymmetric finite-element models ${ }^{2}$ of the soft tissue in the vicinity of the test location (Fig. 1). The soft tissue thickness at respective test locations was estimated based on magnetic resonance images or computed tomography scans of the residual limb (Table I). The radial dimension of the simulated soft tissue was at least twice the soft tissue thickness to minimize the edge effects. 

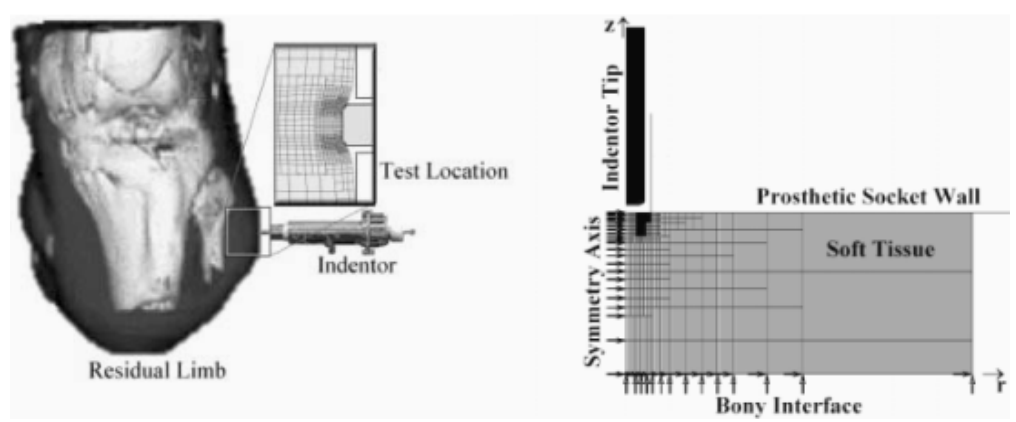

Fig. 1. Soft tissue indentation experiment (left) and axisymmetric finite-element model simulating the soft tissue indentation process (right).

Table I Soft tissue thickness measures at the respective test locations

\begin{tabular}{|c|c|c|c|c|c|c|c|c|c|}
\hline & \multicolumn{9}{|c|}{ Tissue Thickness [tum] } \\
\hline Test Location & Subjest $1^{\circ}$ & Subject $2^{\circ}$ & Subject $26^{\circ}$ & Subject $3^{4}$ & Subject $4^{9}$ & Subject $5 a^{\circ}$ & Subject $5 b^{*}$ & Subject $6^{*}$ & Subject $7^{*}$ \\
\hline Distal Poplincal & 47.8 & 59.8 & 63.9 & 32.2 & 40.8 & 52.9 & 51.9 & 65.9 & 53.6 \\
\hline Prox. Poplineal Area & 34.9 & 30.8 & 51.1 & 22.5 & 38.5 & 36.1 & 44.0 & 46.2 & 35.9 \\
\hline Dist. Medial Tibial Flare & 31.9 & 19.2 & 12.4 & $n / a^{+}$ & 23.6 & 22.3 & 24,0 & 31.8 & 32.9 \\
\hline Prox Medial Tibial Flare & 12.7 & 10.2 & 12.1 & $n f a^{+}$ & 8.9 & 16.1 & 15.4 & 23.4 & 9.5 \\
\hline Dist. Litteral Tibial Flare & 17.8 & 35.8 & 44.2 & $n \mathrm{fa}^{+}$ & 18.0 & 17.6 & 19.1 & 30.2 & 21.0 \\
\hline Prox Lateral Tibial Flare & 22.5 & 7.3 & 16.9 & $n / a^{+}$ & 13.7 & 22.5 & $\mathrm{n} / \mathrm{e}^{2}$ & $n / e^{i}$ & $n / e^{2}$ \\
\hline Fibular Head & 18.7 & 18.8 & 32.5 & $n \mathrm{n}^{+}$ & 16.7 & 16.3 & 7.0 & 11.4 & 84 \\
\hline Fibular Shaft & 42.2 & 52.4 & 62.1 & 34.5 & 11.5 & 17.2 & 19.3 & 28.8 & 20.5 \\
\hline Patellar Tendon & 8.6 & 6.1 & 14.5 & 10.9 & 8.3 & 12.6 & 7,4 & 12.6 & 89 \\
\hline Medial Aspect & 13.0 & $n / a^{\prime}$ & 18.9 & $n / a^{+}$ & 23.6 & 45.7 & $n i e^{3}$ & $n / k^{i}$ & $n / e^{3}$ \\
\hline Lateral Aspect & 48.8 & 14.9 & 20.8 & 26.1 & 17.9 & 17.1 & $\mathrm{n} / \mathrm{e}^{2}$ & $n / e^{j}$ & $n / e^{i}$ \\
\hline Medial Femoral Condyle & nie $e^{2}$ & nie & $n / e^{2}$ & $\pi e^{t}$ & nie $e^{*}$ & $n / e^{t}$ & 10.1 & 8.2 & 4.4 \\
\hline
\end{tabular}

- Siemens Magnetom MR: 192x256 pixels corresponding to 10x10 $\mathrm{cm}^{2}$

- GE Signa MR: $512 \times 256$ pixels corresponding to $20 \times 20 \mathrm{~cm}^{2}$

Siemens Somatom CT: 1-1.5 mm resolution; CT scans were used for these two subjects due to the presence of indwelling metal

n/a: not available - excluded from tissue testing due to extreme subject sensitivity to indentation.

n/e: non-existing - no test port existed at this anatomical location.

In addition to the soft tissue, the finite-element model included the indentor tip (4.9-mm diameter) and prosthetic socket as rigid bodies in contact with soft tissue. The soft tissue was assumed to stick the rigid bony interface (fixed radial and axial displacements), was fixed in the radial direction along the symmetry axis $(z=0)$, and was free at the far radial end. Preliminary analyses identified little variation in the soft tissue reaction force for frictional versus frictionless contact; to minimize computational effort, friction was neglected in subsequent analyses.

The soft tissue was approximated using four-node quadrilateral axisymmetric elements. A master mesh was created based upon systematic mesh refinement (i.e., convergence of the indentor reaction force to within $2 \%$ of that of the previous coarser mesh). The soft tissue in this refined master mesh conformed to the indentor geometry for large indentations. The master mesh was subsequently modified (with purged elements or scaling and/or moving modified boundaries) to correspond to the tissue thickness of the respective test location as measured by the imaging studies. The mesh under the indentor tip contained elements with edge lengths of $0.1 \mathrm{~mm}$ so as to model the contact and highest

IEEE Transactions on Neural Systems and Rehabilitation Engineering, Vol 11, No. 1 (March 2003): 43-53. DOI. This article is (C) Institute of Electrical and Electronics Engineers (IEEE) and permission has been granted for this version to appear in e-Publications@Marquette. Institute of Electrical and Electronics Engineers (IEEE) does not grant permission for this article to be further copied/distributed or hosted elsewhere without the express permission from Institute of Electrical and Electronics Engineers (IEEE). 
stress and strain gradients accurately. Other regions of the mesh contained larger elements. The transition between these varying sized elements incorporated nodal ties, thereby retaining regularly shaped elements. The number of elements in the various finiteelement models ranged from 328 to 490 (383 to 562 nodes), depending on the soft tissue thickness at the respective site.

The bulk soft tissue was approximated as a single homogeneous, isotropic (in the undeformed configuration), nonlinear elastic, incompressible material represented by the James-Green-Simpson strain energy density function, ${ }^{46,47-48,49,50,52-53,54}$ as follows:

$$
\begin{aligned}
W= & C_{10}\left(I_{1}-3\right)+C_{01}\left(I_{2}-3\right) \\
& +C_{11}\left(I_{1}-3\right)\left(I_{2}-3\right) \\
& +C_{20}\left(I_{1}-3\right)^{2}+C_{30}\left(I_{1}-3\right)^{3}
\end{aligned}
$$

where $W$ is the strain energy density (energy-per-unit undeformed volume), $I_{1}$ and $I_{2}$ are the first and second invariants of Green-Lagrange finite strain tensor, and $C_{i j}$ are the nonlinear elastic material coefficients to be determined.

Due to incompressible material and axisymmetry assumptions, two of the three stretches are dependent, and the two invariants of Green-Lagrange strain tensor $I_{1}$ and $I_{2}$, are equivalent-as shown in the appendix. The general James-Green-Simpson material model was reduced from the five-parameter model shown in (1) to a three-parameter model by 1) equating the first-order material coefficients (in terms of the strain invariants) $C_{10}=C_{01}=C_{1}$ and 2 ) equating the second-order material coefficients (in terms of the strain invariants) $C_{11}=C_{20}=C_{2}$. The third-order material coefficient (in terms of strain invariants) was referenced as $C_{3}=C_{30}$.

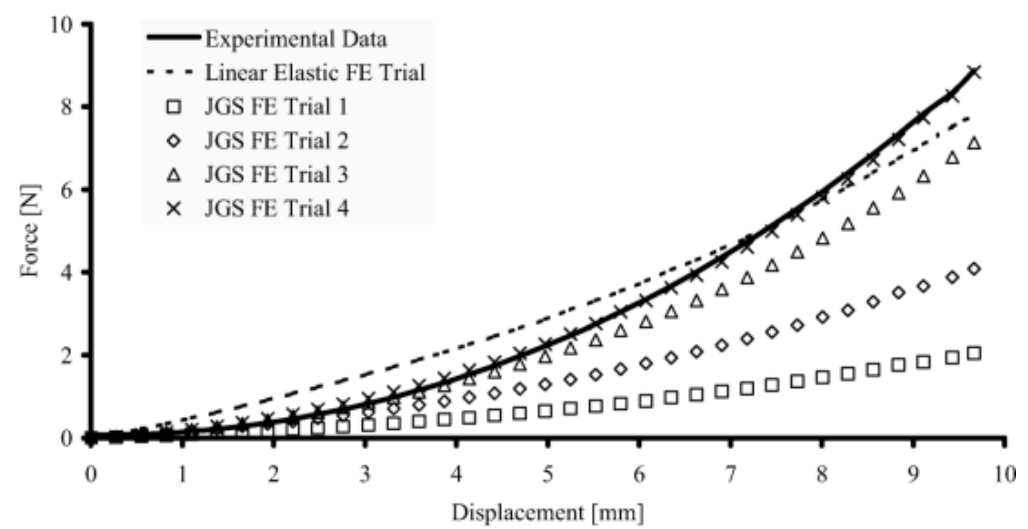

IEEE Transactions on Neural Systems and Rehabilitation Engineering, Vol 11, No. 1 (March 2003): 43-53. DOI. This article is @ Institute of Electrical and Electronics Engineers (IEEE) and permission has been granted for this version to appear in e-Publications@Marquette. Institute of Electrical and Electronics Engineers (IEEE) does not grant permission for this article to be further copied/distributed or hosted elsewhere without the express permission from Institute of Electrical and Electronics Engineers (IEEE). 
NOT THE PUBLISHED VERSION; this is the author's final, peer-reviewed manuscript. The published version may be accessed by following the link in the citation at the bottom of the page.

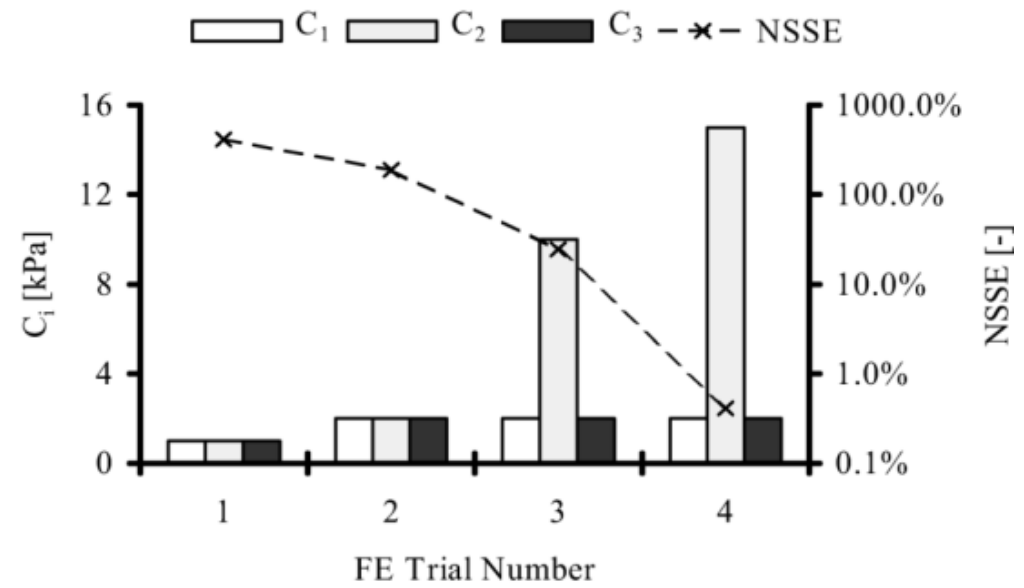

Fig. 2. Force-displacement data during the search for nonlinear elastic material properties (Subject 1, distal popliteal region, thickness $=47.8 \mathrm{~mm}$, indentation rate $=10 \mathrm{~mm} / \mathrm{s})(\mathrm{a})$. For reference, the results for an optimized linear elastic material formulation $(E=73 \mathrm{kPa}, \nu=0.5$, NSSE $=13.5)$ are also shown. The corresponding soft tissue material properties (bars) and associated NSSE (dashed line), during the search is shown in (b).

In addition to the material nonlinearity, additional nonlinearities (namely, large displacements and strains) were imposed on the tissue during the experimental protocol and were included in the finite-element analyses.

To simulate the soft tissue indentation, the indentor tip was positioned using the initial velocity option of the finite-element software, with little computational effort. This tip was then displaced at a rate of 1,5 , or $10 \mathrm{~mm} / \mathrm{s}$ until the maximum experimental displacement was imposed (35 equal time increments). The convergence criterion was such that the maximum residual force was less than $2 \%$ of the maximum nodal force for each time step. The soft tissue reaction force under the indentor tip as a function of tip displacement was then contrasted with the experimental force-displacement data. This comparison enabled identification of the material coefficients.

The heuristic search process for a suitable set of material coefficients began with an initial guess, $C_{1}=C_{2}=C_{3}=1 \mathrm{kPa}$. Increases in any of the material coefficients resulted in an increase in the strain energy density and the reaction force exerted by the tissue on the indentor tip. Preliminary sensitivity analysis on the material coefficients indicated that $C_{1}$ accounted for the initial stiffness of the soft tissue at low strains, $C_{2}$ accounted for the stiffening of the tissue with increasing strain, and $C_{3}$ caused increased stiffening at large strains. 
Due to large variations in soft tissue thickness and maximum tissue displacement during experimentation, a robust efficient optimization algorithm was not identified. During the subsequent manual material coefficient search process, two guidelines were followed.

- $\quad C_{1}$ was modified to simulate the experimental behavior at low strains (i.e., small indentation).

- $\quad C_{2}$ and $C_{3}$ were then modified, depending on the curvature of the force-displacement relationship, to approximate the tissue stiffness at higher strains.

Due to the highly nonlinear nature of the problem, this search process was iterative. These iterations continued until the normalized sum of square error (NSSE) between the experimental and the finite-element indentor reaction force was less than $1 \%$ or appeared to have converged. The NSSE is defined as

$$
\mathrm{NSSE}=\sum_{i=1}^{35}\left(\frac{F_{\mathrm{exp}_{i}}-F_{\mathrm{fe}_{\mathrm{i}}}}{F_{\mathrm{exp}_{\max }}}\right)^{2}
$$

where $F_{\text {exp }}$ is the experimentally measured indentor reaction force, $F_{\mathrm{fe}}$ is the finite-element indentor reaction force, $i$ is the respective time step, and $F_{\exp _{\text {max }}}$ is the maximum experimental reaction force to indentation.

\section{SECTION III.}

\section{Results}

The James-Green-Simpson nonlinear elastic constitutive equation was used to simulate the nonlinear force-displacement behavior of residual limb soft tissues, as measured during cyclic rate-controlled indentation. The results of a representative material coefficient search are summarized in Fig. 2. For the initial estimate of material coefficients (Trial 1) $C_{1}=C_{2}=C_{3}=1 \mathrm{kPa}$, the simulated force deformation was softer than the experimental data, and the stiffening behavior is less pronounced. In the second trial, the increase in , $C_{1} C_{2}$, and $C_{3}$ to $2 \mathrm{kPa}$ resulted in a steeper initial slope of the forcedisplacement curve, although pronounced stiffening as the indentation progressed was not observed due to relatively small maximum soft tissue strains in this example. The stiffening behavior was increased in the third and fourth trials, when $C_{2}$ was increased to 10 and 15 
$\mathrm{kPa}$, respectively. As the NSSE for the fourth trial was less than 1\%, the search process was terminated after the fourth trial. The corresponding nonlinear elastic material coefficients and the resultant errors are shown in Fig. 2(b). [For reference, the results of a linear elastic material simulation (i.e., $E=73 \mathrm{kPa}, v=0.5$, NSSE $=13.5 \%$ ) are also shown. Although this is a linear elastic material model, other nonlinearities due to contact, finite strain, large displacements and rotations are present, and contribute to the nonlinear forcedisplacement behavior seen during the simulation.]

The in vivo rate-controlled indentation tests performed on the residual limbs of seven individuals with transtibial amputation yielded 254 force-displacement data sets for simulation. Finite-element models of 14 (6\%) of these data sets failed. Nearly $80 \%$ (11) of these failures were attributed to excessive indentation with respect to the local soft tissue thickness (i.e., indentation exceeded $75 \pm 17 \%$ of the local soft tissue thickness), causing local inside-out elements due to excessive mesh deformation. The remaining three failures occurred at sites where the soft tissue was both thin and stiff and where simulation resulted in soft tissue nodes slipping out of the contact zone (i.e., indentor tip area) due to the frictionless contact assumption. Seven of the failed models were at the patellar tendon region, a pressure-tolerant area with substantial deformation with respect to overall soft tissue thickness. Other failed simulation sites included the fibular head (3), the proximal medial tibial flare (3), and the proximal popliteal (1) regions. Among the 240 simulated data sets, 228 (95\%) were modeled with an NSSE less than 5\% (Fig. 3). Convergence to the desired NSSE level (i.e., less than $1 \%$ or apparent convergence) typically required four to eight iterations.

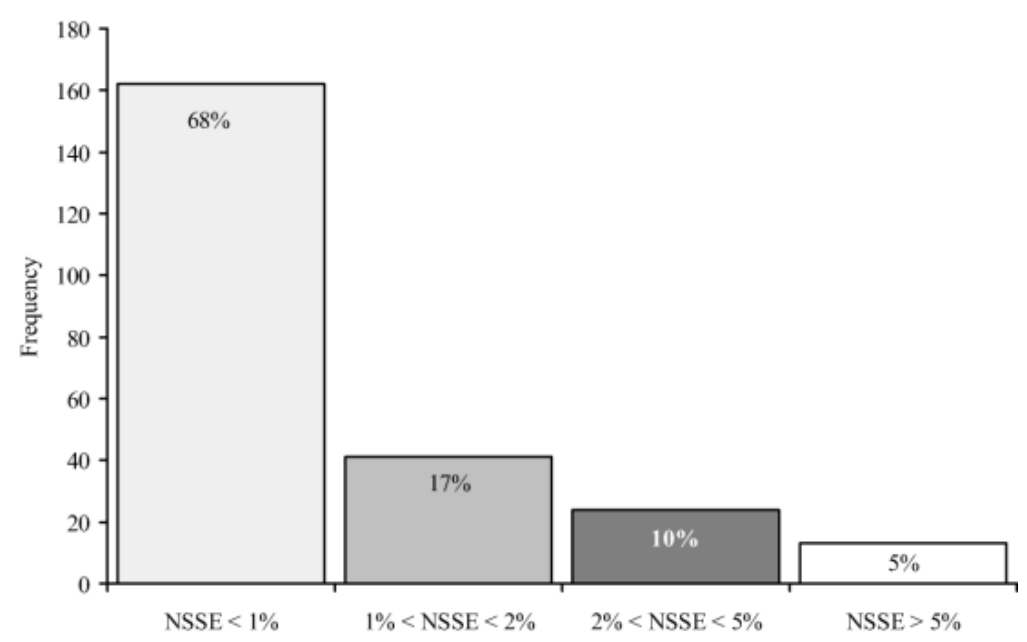

Fig. 3. NSSE distribution for the 240 simulated data sets. 
The NSSEs for these nonlinear elastic material models are summarized in Fig. 4(a) for each of the respective test subjects. With the exception of Subjects $2 b$ and $5 b$, the mean NSSE was less than 1.5\%, with a standard deviation less than $2 \%$. The resultant variability in the NSSE as a function of the respective test site is shown in Fig. 4(b). The mean NSSE exceeded $2 \%$ at the proximal medial tibial flare, proximal lateral tibial flare, and patellar tendon locations. Greater variability in the NSSE was observed at the fibular shaft and proximal medial tibial flare locations. Finally, in Fig. 4(c), the variation in the NSSE is presented in terms of the indentation rate. Although the mean NSSE was similar for all three rates, greater variability was observed at $5 \mathrm{~mm} / \mathrm{s}$.

The variability in the material parameters themselves (as opposed to the variability in the NSSE presented previously) is summarized for two representative subjects, Subjects 5 and 7, in Figs. 5 and 6. The material coefficients differed for the various indentation rates at the same test site. These parameters also varied with test location and test subject.

For the 240 simulated data files (i.e., seven subjects, three indentation rates), the James-Green-Simpson nonlinear elastic material coefficients ranged from $0.01 \leq C_{1} \leq 700$ $\mathrm{kPa}, 0.01 \leq C_{2} \leq 2350 \mathrm{kPa}$, and $0.01 \leq C_{3} \leq 250000 \mathrm{kPa}$.

\section{SECTION IV.}

\section{Discussion and Conclusion}

It has been suggested that linear elastic representation of residual limb soft tissues is a crude approximation, and that a more accurate description is needed for improved simulation of the residual limb-prosthetic socket interface using finite-element analysis. 3,4,11,12,28,29,55 A finite-element simulation incorporating a linear elastic material formulation [Fig. 2(a)] demonstrated the inability of a linear elastic material formulation to simulate the observed nonlinear material behavior of the soft tissue, supporting the aforementioned claim. In contrast, the James-Green-Simpson nonlinear elastic material model, one of the simplest phenomenological nonlinear elastic material formulations available in literature, was capable of simulating the experimentally observed nonlinear compressive force-displacement behavior of the residual limb bulk soft tissues of individuals with transtibial amputation. The NSSE was less than 5\% for 95\% (228 of 240) of the data files simulated using this nonlinear elastic material model.

For models with an NSSE greater than 5\% [Fig. 3], the experimental data sets exhibited tissue softening with increasing indentation, which could not be simulated with 
the assumed material model. Model failure, or the inability to simulate the entire experimental indentation range, was due to either indentation exceeding $75 \%$ of the soft tissue thickness or thin stiff soft tissue at the respective test location.
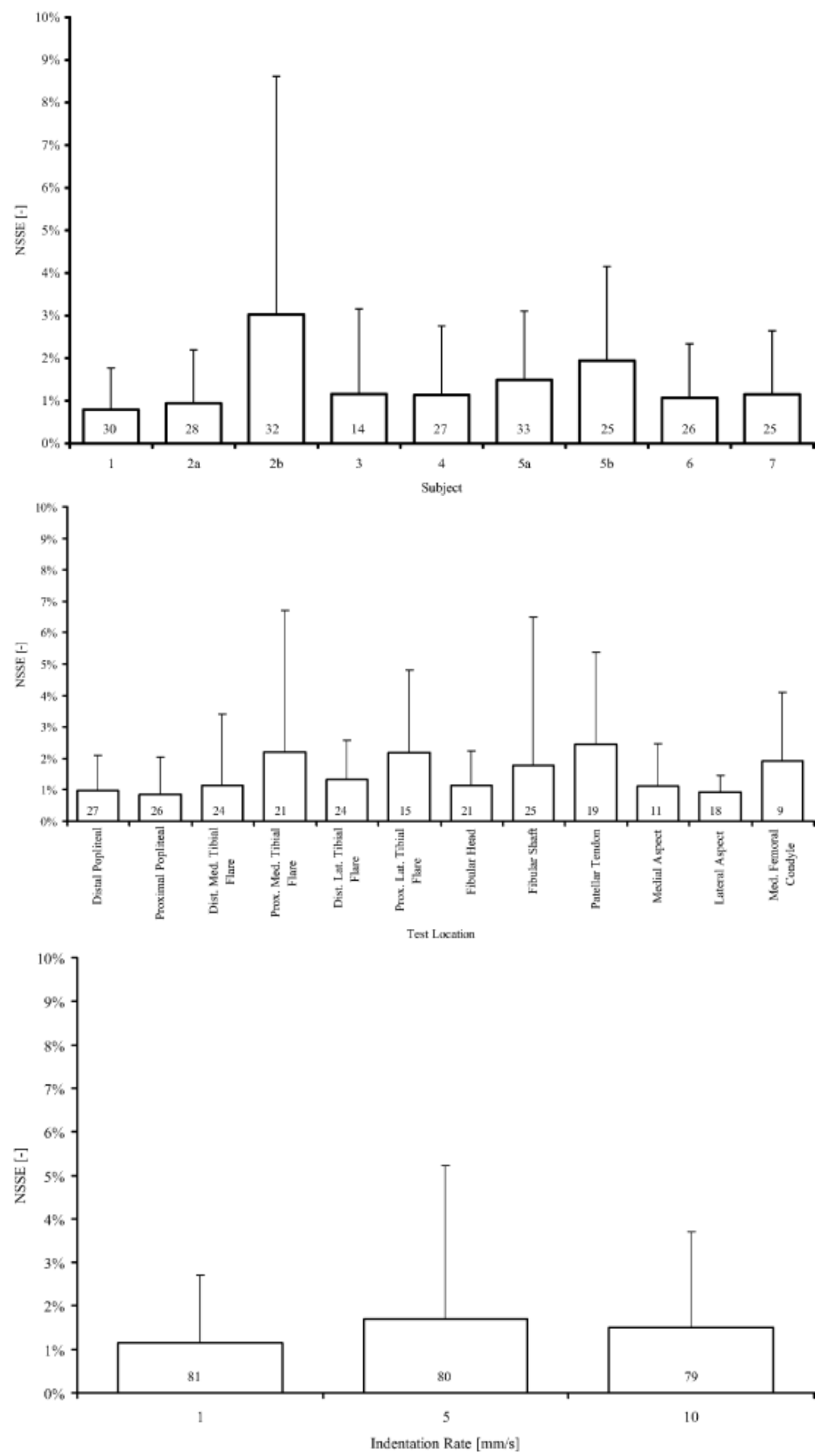

Fig. 4. Mean NSSE and the corresponding standard deviation and sample sizes (numbers in bars) for data from (a) each test subject, (b) location, and (c) indentation rate.

IEEE Transactions on Neural Systems and Rehabilitation Engineering, Vol 11, No. 1 (March 2003): 43-53. DOI. This article is (C) Institute of Electrical and Electronics Engineers (IEEE) and permission has been granted for this version to appear in e-Publications@Marquette. Institute of Electrical and Electronics Engineers (IEEE) does not grant permission for this article to be further copied/distributed or hosted elsewhere without the express permission from Institute of Electrical and Electronics Engineers (IEEE). 
A shown by the NSSE of the simulated tissue indentation data [Fig. 4], several observations can be made.

- The NSSE values, a measure of how well the experimental behavior was simulated with the converged nonlinear elastic material coefficients, varied among subjects, test sites, and indentation rates.

- With the exception of Subjects $2 \mathrm{~b}$ (mean NSSE 3\%) and $5 \mathrm{~b}$ (mean NSSE 1.9\%), the mean NSSE was less than 1.5\%. Thus, the soft tissues of the residual limbs of the majority of the tested subjects can be simulated by the James-Green-Simpson material model.

- The simulation of the distal and proximal popliteal, distal medial and lateral tibial flares, fibular head, and medial and lateral aspects of the residual limbs consistently resulted in low NSSE with little variability. The soft tissue at these test sites, in comparison with other test sites, seems particularly suited to the James-GreenSimpson nonlinear elastic material model.

- The mean NSSE at indentation rates of 1,5 , and $10 \mathrm{~mm} / \mathrm{s}$ was relatively constant, although greater variation was observed at $5 \mathrm{~mm} / \mathrm{s}$. The James-Green-Simpson material formulation can therefore simulate compressive force-displacement characteristics of residual limb soft tissues for all of the experimental indentation rates.

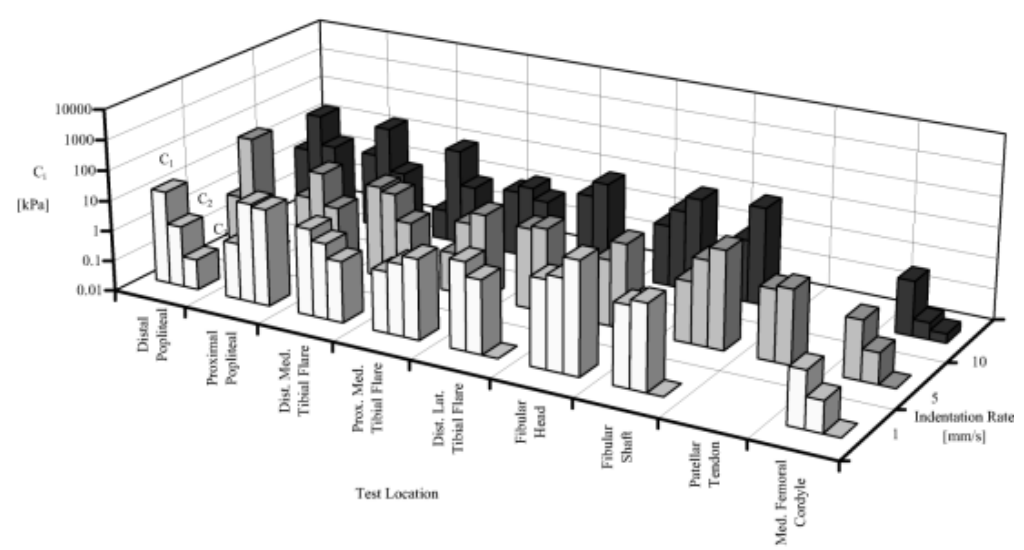

Fig. 5. James-Green-Simpson material coefficients for Subject 7. 
NOT THE PUBLISHED VERSION; this is the author's final, peer-reviewed manuscript. The published version may be accessed by following the link in the citation at the bottom of the page.
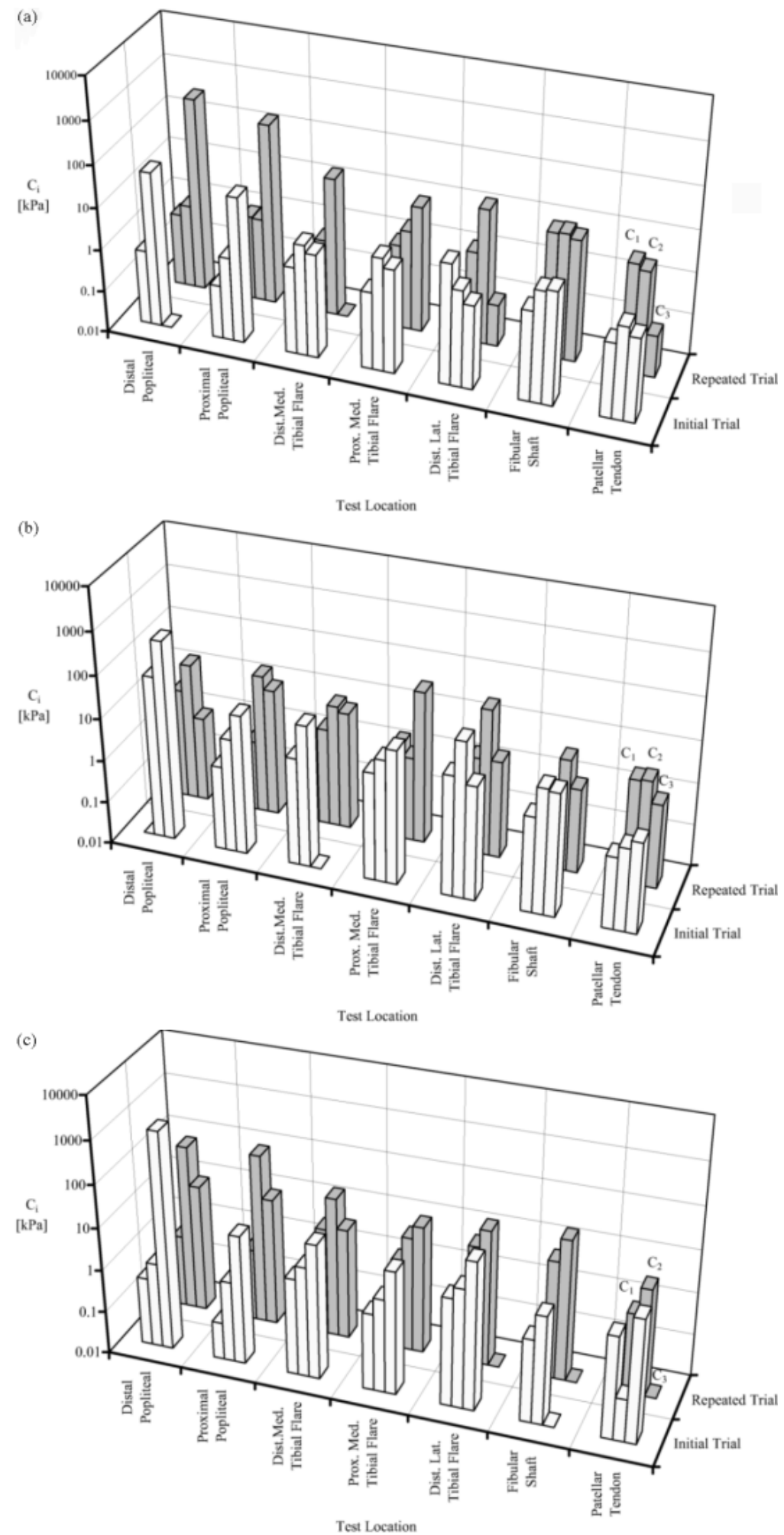

Fig. 6. James-Green-Simpson material coefficients for (a) $1 \mathrm{~mm} / \mathrm{s}$, (b) $5 \mathrm{~mm} / \mathrm{s}$, and (c) $10 \mathrm{~mm} / \mathrm{s}$ for repeated trials performed 20 months apart on Subject 5.

IEEE Transactions on Neural Systems and Rehabilitation Engineering, Vol 11, No. 1 (March 2003): 43-53. DOI. This article is (C) Institute of Electrical and Electronics Engineers (IEEE) and permission has been granted for this version to appear in e-Publications@Marquette. Institute of Electrical and Electronics Engineers (IEEE) does not grant permission for this article to be further copied/distributed or hosted elsewhere without the express permission from Institute of Electrical and Electronics Engineers (IEEE). 
In addition to the investigation of the NSSE, the corresponding material coefficients were also summarized for Subject 7 (Fig. 5), a representative subject in terms of NSSE. With the exception of the medial femoral condyle, the experimental force-displacement curve was not observed to "stiffen" with increased indentation rate 28 -as might be expected for a classic viscoelastic material. As such, while the estimated material coefficient varied with indentation rate, no consistent rate trends were observed. Similar variability in the estimated material coefficients was also observed between test locations. This variability in the converged nonlinear elastic material coefficients between sites and with indentation rate indicate that indentor tests and subsequent material property estimation is needed for each test location and loading rate of interest for accurate simulation of soft tissue compressive behavior.

The material coefficients were also summarized for Subject 5, as this subject completed the experimental protocol twice over a 20-month interval. Changes in the subject's residual limb during this period necessitated the design and fabrication of a new test prosthesis for the latter trials. Therefore, it was not surprising that the material coefficients differed for the two trials [Fig. 6]. This time-dependent variability in material coefficients (at each of the respective indentation rates) was not consistent with the changes in soft tissue thickness observed over this same time period.

The time-dependent variability in the residual limb itself is routinely observed. The volume of a lower extremity amputee's residual limb may vary substantially over the course of the day, as commonly seen by the need for addition and/or removal of stump socks. The residual limb soft tissues are influenced by many factors, including diet, activity level, and adverse medical conditions. Such variations confound attempts to assess material property variation with indentation rate, as the respective test protocols at the specific indentation rates were conducted at weekly intervals. Therefore, the variability in the resultant nonlinear elastic material coefficients with subject, location, and indentation rate preclude these coefficients from being readily extrapolated to other individuals, other sites, or other rates. In addition, the time dependent changes in the residual limb itself indicate that the respective material coefficients should perhaps also not be applied to the same individual some time after testing. Further testing is needed to determine the variability of soft tissue response to indentation with time.

As shown in, ${ }^{28}$ the residual limb soft tissues did not consistently behave as a classical viscoelastic solid (i.e., more compliant at slower indentation rates), perhaps due to the aforementioned variability with time and the fact that the test protocol spanned a fourto five-week period. Therefore, as expected, the nonlinear elastic material coefficients were 
not observed to increase with the increasing indentation rate for a given location and subject.

The force-displacement data from the rate-controlled indentation tests were simulated using nonlinear finite-element models. Nonlinear models-by nature-are iterative and therefore computationally more expensive than linear models. For this study, each finite-element simulation required 35 time steps, and each time step required one or more stiffness matrix reevaluations. Due to the material and geometric nonlinearities, the search for a suitable (i.e., NSSE $\leq 1 \%$ ) set of material coefficients required multiple iterations. Thus, although the material formulation was a relatively simple nonlinear model with only three independent coefficients, considerable calculation was required to estimate the nonlinear elastic material coefficients.

The nonlinear elastic material coefficients were estimated using a manual search process. The material property search process may be automated to reduce user interaction and potentially accelerate the search. Vetrano and Silver-Thorn ${ }^{44,45}$ achieved some success with an automated material coefficient search algorithm (Hooke-Jeeves). This algorithm is simple and robust but not very efficient for this application. As the residual limb tissues are nonlinear and the level of nonlinearity varies for each test location (i.e., due to the indentation magnitude, the soft tissue thickness, and the resultant tissue strains), basic properties of the strain energy density function should be incorporated into an automated search process to maximize efficiency.

Some commercial finite-element software packages ${ }^{56,57}$ use the experimental engineering stress and strain data to extract the material coefficients for a specified material formulation. However, these algorithms require test specimens with regular geometry and controlled loading (e.g., uniaxial, biaxial, simple shear). Such automated techniques were not amenable for the in vivo indentation data.

There are some limitations to the modeling efforts presented. The individual soft tissue constituents (e.g., skin, fat and muscle) at the test location were modeled as a single, homogeneous, isotropic, nonlinear elastic material. The behavior of the individual constituents and their interaction with each other were not modeled. The James-GreenSimpson nonlinear elastic material formulation is a phenomenological (empirical) model that approximates the macro-mechanical nonlinear behavior and ignores the microstructure and mechanisms contributing to the observed nonlinear behavior. The converged nonlinear elastic material coefficients are therefore not indicative of residual limb soft tissue physiology. (The only physical interpretation of the nonlinear elastic 
material coefficients is that $C_{1}$ provides an indication of initial soft tissue stiffness at small indentations, $C_{2}$ indicates the relative stiffening as the indentation progresses, and $C_{3}$ reflects large strain effects.) Structural and microstructural material formulations require more extensive experimentation to determine the structural parameters and associated interactions. Such formulations also tend to require greater computational effort than phenomenological models.

A potential source of error for these models was the axisymmetric approximation of the residual limb geometry at the respective test site and the associated loading (i.e., tissue indentation). Exterior (i.e., skin) and interior (i.e., bone) surface curvatures of the lower extremity residual limb are not axisymmetric. However, the effects of these curvatures on the simulated force-displacement behavior were found to be negligible. ${ }^{58}$ While the loading for the tissue indentation trials was approximately axisymmetric, the physiologic loading condition of a residual limb soft tissue in a prosthetic socket, in general, is not axisymmetric. Subsequent simulation of the residual limb tissues, using these axisymetrically derived material coefficients, subjected to more realistic multiaxial physiologic loading may therefore be suspect.

The frictionless contact assumption between the indentor tip and soft tissue resulted in three simulation failures in 254 attempts. The soft tissue contact nodes rarely slipped with respect to the rigid indentor tip. Errors due to the frictionless contact assumption are therefore believed to be minimal.

Finally, the nonlinear material of residual limb soft tissue was modeled by the James-Green-Simpson formulation, an elastic formulation. Time-dependent phenomena, such as creep and relaxation, as well as hysteresis during cyclic loading, have been observed for residual limb soft tissues. ${ }^{28,55}$ These behaviors cannot be simulated with the present elastic material model. Investigation of an extended form of the same nonlinear material formulation to include the viscoelastic properties of the soft tissue is ongoing. ${ }^{59}$ With the addition of viscoelastic material properties, a wider range of loading spectra can perhaps be simulated that may further our understanding of the residual limb soft tissue response to compressive loading and residual limb-prosthetic socket interface biomechanics.

\section{ACKNOWLEDGMENT}


The authors would like to thank J. Bessette and the VA Medical Center (Milwaukee, WI), N. Anderson, Dr. R. Prost, and the Medical College of Wisconsin (Milwaukee) for their assistance with the imaging studies.

\section{Appendix}

In cylindrical coordinates, one may select indexes such that $1=$ radial coordinate $(r), 2=$ angular coordinate $(\theta)$, and $3=$ axial coordinate $(z)$. Thus, for an axisymmetric problem, the angular displacement $\left(u_{2}\right)$ is identically zero. In addition, the derivative of any quantity in angular direction vanishes (e.g., $\left.\partial(\cdot) / \partial X_{\theta}=\partial(\cdot) / \partial x_{\theta}=0\right)$.

Using the notation of Malvern [60], 4. the stretch (in the Lagrangian sense) is defined as

$$
\Lambda_{(i)}^{2}=1+2 E_{(i)(i)}
$$

where $E_{(i)(i)}$ refers to the diagonal (no summation) elements of Green-Lagrange finite strain tensor. The diagonal elements of Green-Lagrange finite strain tensor in an axisymmetric problem become

$$
\begin{aligned}
& E_{r r}=\frac{\partial u_{r}}{\partial X_{r}}-\frac{1}{2}\left[\left(\frac{\partial u_{r}}{\partial X_{r}}\right)^{2}+\left(\frac{\partial u_{z}}{\partial X_{r}}\right)^{2}\right] \\
& E_{\theta \theta}=0 \\
& E_{z z}=\frac{\partial u_{z}}{\partial X_{z}}-\frac{1}{2}\left[\left(\frac{\partial u_{r}}{\partial X_{z}}\right)^{2}+\left(\frac{\partial u_{z}}{\partial X_{z}}\right)^{2}\right] .
\end{aligned}
$$

As such, the stretches in (A1) become

IEEE Transactions on Neural Systems and Rehabilitation Engineering, Vol 11, No. 1 (March 2003): 43-53. DOI. This article is (c) Institute of Electrical and Electronics Engineers (IEEE) and permission has been granted for this version to appear in e-Publications@Marquette. Institute of Electrical and Electronics Engineers (IEEE) does not grant permission for this article to be further copied/distributed or hosted elsewhere without the express permission from Institute of Electrical and Electronics Engineers (IEEE). 


$$
\begin{aligned}
& \Lambda_{r}^{2}=1+2 \frac{\partial u_{r}}{\partial X_{r}}-\left[\left(\frac{\partial u_{r}}{\partial X_{r}}\right)^{2}+\left(\frac{\partial u_{z}}{\partial X_{r}}\right)^{2}\right] \\
& \Lambda_{\theta}^{2}=1 \\
& \Lambda_{z}^{2}=1+2 \frac{\partial u_{z}}{\partial X_{z}}-\left[\left(\frac{\partial u_{r}}{\partial X_{z}}\right)^{2}+\left(\frac{\partial u_{z}}{\partial X_{z}}\right)^{2}\right] .
\end{aligned}
$$

For an incompressible material

$$
I_{3}=\lambda_{1}^{2} \lambda_{2}^{2} \lambda_{3}^{2}=1
$$

As $\Lambda_{2}=\lambda_{2}=1$ for axisymmetric problems (i.e., zero angular displacement)

$$
I_{3}=\lambda_{r}^{2} \lambda_{z}^{2}=1
$$

or

$$
\lambda_{z}^{2}=\frac{1}{\lambda_{r}^{2}}
$$

Substituting $\Lambda_{2}=\Lambda_{\theta}=\lambda_{2}=1$ and (A6) into the equations for the invariants of the GreenLagrange finite strain tensor $I_{1}$ and $I_{2}$

$$
\begin{array}{cc}
I_{1}= & \lambda_{1}^{2}+\lambda_{2}^{2}+\lambda_{3}^{2}=\lambda_{r}^{2}+\lambda_{\theta}^{2}+\lambda_{z}^{2} \\
I_{2}= & \lambda_{1}^{2} \lambda_{2}^{2}+\lambda_{2}^{2} \lambda_{1}^{2}+\lambda_{1}^{2} \lambda_{3}^{2}=\lambda_{r}^{2}+\lambda_{\theta}^{2}+\lambda_{z}^{2}
\end{array}
$$

we find that 


$$
\begin{aligned}
& I_{1}=\lambda_{r}^{2}+1+\frac{1}{\lambda_{r}^{2}} \\
& I_{2}=\lambda_{r}^{2}+\frac{1}{\lambda_{r}^{2}}+1 .
\end{aligned}
$$

(A8)

Thus, the two remaining independent invariants of Green-Lagrange strain tensor, $I_{1}$ and $I_{2}$ are equivalent for an incompressible material under axisymmetric loading conditions.

As $I_{1}=I_{2}$, the strain energy density of the James-Green-Simpson material model [(1) in this paper] may be simplified to

$$
W=C_{I}(I-3)+C_{J}(I-3)^{2}+C_{K}(I-3)^{3}
$$

where the new material coefficients $C_{I}$ may be expressed in terms of the original coefficients $C_{i j}$ as

$$
\begin{aligned}
C_{I} & =C_{10}+C_{01} \\
C_{J} & =C_{11}+C_{20} \\
C_{K} & =C_{30} .
\end{aligned}
$$

In this study, $C_{10}=C_{01}=C_{1}\left(\right.$ or $\left.\left.C_{I}=2 C_{1}\right)\right), C_{11}=C_{20}=C_{2}\left(\right.$ or $\left.C_{J}=2 C_{2}\right)$ ), and $C_{3}=C_{30}=$ $C_{K}$ were arbitrarily assigned.

\section{References}

1F. T. Hoaglund, H. E. Jergesen, L. Wilson, L. W. Lamoreux, R. Roberts, "Evaluation of the problems and needs of veteran lower-limb amputees in the San Francisco Bay area during the period $1977>$ ", J. Rehabil. Res. Dev., vol. 20, pp. 57-71, 1983.

2J. E. Sanders, "Interface mechanics in external prosthetics: Review of interface stress measurement techniques", Med. Biol. Eng. Comput., vol. 33, pp. 509-516, 1995.

3M. B. Silver-Thorn, J. W. Steege, D. S. Childress, "A review of prosthetic interface stress investigations", J. Rehabil. Res. Dev., vol. 33, pp. 253-266, 1996. 
4J. E. Sanders, C. H. Daly, "Measurement of stresses in three orthogonal directions at the residual limbprosthetic socket interface", IEEE Trans. Rehab. Eng., vol. 1, pp. 79-85, June 1993.

5J. E. Sanders, C. H. Daly, "Interface pressures and shear stresses; sagittal plane angular alignment effects in three trans-tibial amputee case studies", Prosthet. Orthotics Int., vol. 23, pp. 21-29, 1999.

6J. E. Sanders, D. Lam, A. J. Dralle, R. Okumura, "Interface pressures and shear stresses at thirteen socket sites on two persons with transtibial amputation", J. Rehabil. Res. Dev., vol. 34, pp. 19-43, 1997.

7J. E. Sanders, D. M. Bell, R. M. Okumura, A. J. Dralle, "Effects of alignment changes on stance phase pressures and shear stresses on transtibial amputees: Measurements from 13 transducer sites", IEEE Trans. Rehab. Eng., vol. 6, pp. 21-31, Mar. 1998.

$8 \mathrm{M}$. Zhang, A. R. Turner-Smith, A. Tanner, V. C. Roberts, "Clinical investigation of pressure and shear stress on the trans-tibial stump with a prosthesis", Med. Eng. Phys., vol. 20, pp. 188-198, 1998.

9S. G. Zachariah, J. E. Sanders, "Interface mechanics in lower-limb external prosthetics: A review of finite element methods", IEEE Trans. Rehab. Eng., vol. 4, pp. 288-302, Dec. 1996.

${ }^{10}$ M. Zhang, A. F. T. Mak, V. C. Roberts, "Finite element modeling of a residual lower-limb in a prosthetic socket: A survey of development in the first decade", Med. Eng. Phy., vol. 20, pp. 360-373, 1998.

11J. W. Steege, D. S. Schnur, D. S. Childress, "Estimation of pressure at the below-knee socket by finite element analysis", Proc. Bioengineering Conf. (ASME-BED), vol. 4, pp. 39-43, 1987.

12J. W. Steege, D. S. Schnur, L. R. Van Vorhis, J. S. Rovick, "Finite element analysis as a method of pressure estimation at the below-knee socket interface", Proc. 10th Annu. RESNA Conf., pp. 814-816, 1987.

13J. W. Steege, D. S. Childress, "Finite element estimation of pressure at the below-knee socket interface", Report ISPO Workshop CAD/CAM Prosthetics Orthotics, pp. 71-82, 1988.

${ }^{14} \mathrm{M}$. Zhang, M. Lord, A. R. Turner-Smith, V. C. Roberts, "Development of a nonlinear finite element modeling of the below-knee prosthetic socket interface", Med. Eng. Phys., vol. 17, pp. 559-566, 1995.

15P. K. Commean, K. E. Smith, M. W. Vannier, B. A. Szabo, R. L. Actis, "Finite element modeling and experimental verification of lower extremity shape change under load", J. Biomech., vol. 30, pp. 531-536, 1997.

16V. L. Houston, G. Luo, C. P. Mason, A. C. Beattie, K. P. LaBlanc, M. Garbarini, "Tissue biomechanical studies for prosthetic socket design", Proc. Bioengineering Conf. (ASME-BED), vol. 35, pp. 245246, 1997.

${ }^{17}$ C. Fisher, G. Simpson, D. Reynolds, "Development of a finite element model of a trans-tibial socket linerAn initial study", Biomed. Sci. Instrum., vol. 35, pp. 39-44, 1990.

18S. G. Zachariah, J. E. Sanders, "Pre-stresses due to trans-tibial socket donning: A nonlinear finite element analysis with contact", vol. 1, pp. 648, 1999.

${ }^{19}$ Y. Seguchi, M. Tanaka, Y. Akazawa, A. Nakagawa, I. Kitayama, "Finite element analysis and load identification of above-knee prosthesis socket", Proc. 4th Int. ANSYS Conf. Pt. 2, pp. 12.31-12.44, 1989.

20J. M. Brennan, D. S. Childress, "Finite element and experimental investigation of above-knee amputee limb/prosthesis systems: A comparative study", Proc. Bioengineering Conf. (ASME-BED), vol. 20, pp. 547-550, 1991.

${ }^{21}$ A. F. T. Mak, Y. M. Yu, M. L. Hong, C. Chan, "Finite element models for analyzes of stresses within aboveknee stumps", Proc. 7th World Congr. ISPO, pp. 147-148, 1992.

IEEE Transactions on Neural Systems and Rehabilitation Engineering, Vol 11, No. 1 (March 2003): 43-53. DOI. This article is (C) Institute of Electrical and Electronics Engineers (IEEE) and permission has been granted for this version to appear in e-Publications@Marquette. Institute of Electrical and Electronics Engineers (IEEE) does not grant permission for this article to be further copied/distributed or hosted elsewhere without the express permission from Institute of Electrical and Electronics Engineers (IEEE). 
NOT THE PUBLISHED VERSION; this is the author's final, peer-reviewed manuscript. The published version may be accessed by following the link in the citation at the bottom of the page.

${ }^{22}$ M. Zhang, A. F. T. Mak, "Finite element analysis of the load transfer between an above-knee residual limb and its prosthetic socketRoles of interface friction and distal-end boundary conditions", IEEE Trans. Rehab. Eng., vol. 4, pp. 337-346, Dec. 1996.

23T. S. Douglas, S. E. Solomonidis, V. S. P. Lee, W. D. Spence, "Automatic boundary extraction from magnetic resonance images of the residual limb of a trans-femoral amputee", Proc. 19th Annu. Conf. Eng. Med. Biol., vol. 2, pp. 577-579, 1997.

${ }^{24} \mathrm{M}$. Tanaka, Y. Akazawa, A. Nakagawa, I. Kitayama, "Identification of pressure distribution at the socket interface of an above-knee prosthesis", Adv. Eng. Softw., vol. 28, pp. 379-384, 1997.

25M. Zhang, A. F. T. Mak, J. Mak, "Air cushion action at the distal end of above-knee stump with a prosthetic socket", Proc. 20th Annu. Conf. Eng. Med. Biol., vol. 5, pp. 2754-2756, 1998.

26R. Torres-Moreno, Biomechanical analysis of the interaction between the above-knee residual limb an prosthetic socket, 1991.

27W. M. Vannah, D. S. Childress, "Indentor tests and finite element modeling of bulk muscular tissue in vivo", J. Rehabil. Res. Dev., vol. 33, pp. 239-252, 1996.

28M. B. Silver-Thorn, "In vivo indentation of lower extremity soft tissues", IEEE Trans. Rehab. Eng., vol. 7, pp. 268-277, Sept. 1999.

${ }^{29}$ Y. P. Zheng, A. F. T. Mak, "Development of an ultrasound indentation system for biomechanical properties assessment of soft tissue in vivo", Proc. 17th Annu. Conf. Eng. Med. Biol., pp. 1599$1600,1995$.

${ }^{30}$ R. H. Iding, K. S. Pister, R. L. Taylor, "Identification of nonlinear elastic solids by a finite element method", Comput. Methods Appl. Mech. Eng., vol. 4, pp. 121-142, 1974.

${ }^{31}$ H. S. Lin, Y. K. Liu, G. Ray, P. E. Nikravesh, "Systems identification for material properties of the intervertebral joint", J. Biomech., vol. 11, pp. 1-14, 1978.

${ }^{32}$ A. Wineman, D. Wilson, J. W. Melvin, "Material identification of soft tissue using membrane inflation", J. Biomech., vol. 12, pp. 841-850, 1979.

33B. R. Simon, "A direct computational algorithm to estimate in vivo constitutive properties of some cardiovascular structures" in Finite Elements in Biomechanics, AZ, Tucson: Univ. of Arizona, vol. 2, pp. 623-637, 1980.

34R. H. Gallagher, B. R. Simon, P. C. Johnson, J. F. Gross, "Finite elements in stress analysis and estimation of mechanical properties of working heart" in Finite Elements in Biomechanics, New York: Wiley, pp. 127-153, 1982.

35J. M. Guccione, A. D. McCulloch, L. K. Waldman, "Passive material properties of intact ventricular myocardium determined from a cylindrical model", J. Biomed. Eng., vol. 113, pp. 42-55, 1991.

${ }^{36} \mathrm{C}$. W. J. Oomenns, M. R. V. Ratingen, J. D. Janssen, J. J. Kok, M. A. N. Hendricks, "A numericalexperimental method for a mechanical characterization of biological materials", J. Biomech., vol. 26, pp. 617-621, 1993.

37V. P. Novak, F. C. P. Yin, J. D. Humphrey, "Regional mechanical properties of passive myocardium", J. Biomech., vol. 27, pp. 403-412, 1994.

38D. A. Vorp, K. R. Rajagopal, P. J. Smolinski, H. S. Borovetz, "Identification of elastic properties of homogeneous orthotropic vascular segments in distension", J. Biomech., vol. 28, pp. 501-512, 1995.

39J. L. Wang, M. Parnianpour, A. Shirazi-Adl, A. E. Engin, "Development of the viscoleastic finite element model of lumbar motion segment", Proc. ASME-PD, vol. 77, pp. 51-56, 1996.

IEEE Transactions on Neural Systems and Rehabilitation Engineering, Vol 11, No. 1 (March 2003): 43-53. DOI. This article is (c) Institute of Electrical and Electronics Engineers (IEEE) and permission has been granted for this version to appear in e-Publications@Marquette. Institute of Electrical and Electronics Engineers (IEEE) does not grant permission for this article to be further copied/distributed or hosted elsewhere without the express permission from Institute of Electrical and Electronics Engineers (IEEE). 
${ }^{40}$ A. Nagaraj, K. Ramani, B. J. Kane, R. Greene, E. L. Dove, K. B. Chandran, D. D. McPherson, "In-vivo regional assessment of artherosclerotic vascular material properties using three dimensional intravascular ultrasound reconstruction and finite element analysis", Proc. Bioeng. Conf. (ASME$B E D)$, vol. 35, pp. 463-464, 1997.

41D. M. Flynn, G. D. Peura, P. Grigg, A. H. Hoffman, "A finite element based method to determine the properties of planar soft tissue", J. Biomed. Eng., vol. 120, pp. 202-210, 1998.

42J. W. Steege, D. S. Childress, "Finite element modeling of the below-knee socket and limb: Phase II", Proc. Bioeng. Conf. (ASME-BED), pp. 121-129, 1988.

43W. M. Vannah, Indentor tests and finite element modeling of bulk muscular soft tissue in vivo, 1990.

${ }^{44}$ S. L. Vetrano, M. B. Silver-Thorn, "Analysis of residual limb bulk soft tissue behavior using nonlinear finite element methods", Proc. Bioeng. Conf. (ASME-BED), vol. 35, pp. 201-202, 1997.

45S. L. Vetrano, M. B. Silver-Thorn, "Analysis of residual limb bulk soft tissue behavior using nonlinear finite element methods", Proc. 2nd Annu. Conf. Finite Element Methods Bioeng., pp. 29-36, 1997.

46M. Mooney, "A theory of large elastic deformation", J. Appl. Phys., vol. 11, pp. 582-592, 1940.

47R. S. Rivlin, "Large elastic deformations of isotropic materials I: Fundamental concepts", Philos. Trans. R. Soc. London A Math. Phys. Sci., vol. 240, pp. 459-490, 1948.

48R. S. Rivlin, "Large elastic deformations of isotropic materials II: Some uniqueness theorems for pure homogeneous deformation", Philos. Trans. R. Soc. London A Math. Phys. Sci., vol. 240, pp. 491508, 1948.

${ }^{49}$ R. S. Rivlin, "Large elastic deformations of isotropic materials III: Some simple problems in cylindirical polar coordinates", Philos. Trans. R. Soc. London A Math. Phys. Sci., vol. 240, pp. 509-525, 1948.

50J. E. Mark, B. Erman, F. R. Eirich, "The molecular basis of rubberlike elasticity" in Science and Technology of Rubber, San Diego: Academic, pp. 189-210, 1994.

51M. B. Silver-Thorn, Prediction and experimental verification of residual limb/prosthetic socket interface pressures for below-knee amputees, Dec. 1991.

52N. W. Tschoegl, "Constitutive equations for elastomers", J. Polym. Sci., vol. 9, pp. 1959-1970, 1971.

530. H. Yeoh, "Some forms of the strain energy function for rubber", Rubber Chem. Technol., vol. 66, pp. 754-771, 1994.

54R. W. Ogden, "Recent advances in the phenomenological theory of rubber elasticity", Rubber Chem. Technol., vol. 59, pp. 361-383, 1987.

55Y. P. Zheng, A. F. T. Mak, "Extraction of quasilinear viscoelastic parameters for lower limb soft tissues from manual indentation experiment", J. Biomech. Eng., vol. 121, pp. 330-339, 1999.

56Y. P. Zheng, A. F. T. Mak, Mentat 3.3 MARC K7.3New features, MARC Analysis Corporation, 1998.

57Y. P. Zheng, A. F. T. Mak, ABAQUS 5.8-1 release notes, 1998.

${ }^{58} \mathrm{E}$. Tonuk, M. B. Silver-Thorn, "Effect of curvature on lower extremity residual limb models", vol. 1, pp. 639, 1999.

${ }^{59} \mathrm{E}$. Tonuk, M. B. Silver-Thorn, "Nonlinear viscoelastic material property estimation for lower extremity residual limbs", vol. 1, pp. 645, 1999.

${ }^{60} \mathrm{~L}$. E. Malvern, Introduction to the Mechanics of a Continuous Medium, NJ, Englewood Cliffs: PrenticeHall, 1969.

IEEE Transactions on Neural Systems and Rehabilitation Engineering, Vol 11, No. 1 (March 2003): 43-53. DOI. This article is (C) Institute of Electrical and Electronics Engineers (IEEE) and permission has been granted for this version to appear in e-Publications@Marquette. Institute of Electrical and Electronics Engineers (IEEE) does not grant permission for this article to be further copied/distributed or hosted elsewhere without the express permission from Institute of Electrical and Electronics Engineers (IEEE). 